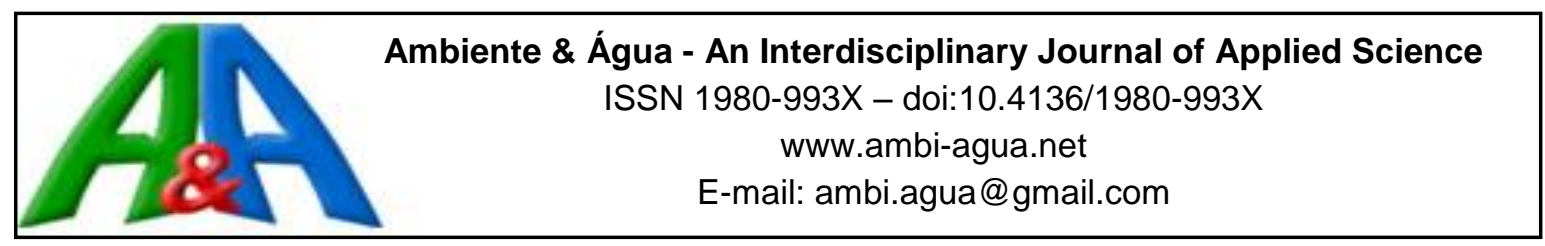

\title{
Contaminação viral e bacteriana em águas subterrâneas na porção aflorante do Aquífero Guaraní, município de Ivoti, RS
}

\author{
doi:10.4136/ambi-agua.2068
}

Received: 20 Dec. 2016; Accepted: 03 Jul. 2017

\begin{abstract}
Roger Bordin da Luz; Rodrigo Staggemeier*; Leila Xavier Sinigaglia Fratta; Larisse Longo; Rafael Schutz; Mayra Cristina Soliman; Mariana Kluge; Rafael Bandeira Fabres; Guilherme Corrêa Schenkel; Fabrício Prestes Bruni; Juliane Deise Fleck; Simone Ulrich Picoli; Fernando Rosado Spilki
\end{abstract}

\author{
Universidade Feevale (FEEVALE), Novo Hamburgo, RS, Brasil \\ Instituto Ciências da Saúde \\ *Autor correspondente: e-mail: rodrigostaggemeier@ feevale.br, \\ rbdaluz@gmail.com, lfratta@gmail.com, larisselongo@ hotmail.com, \\ rafaschutz@yahoo.com.br,mayra_soliman@hotmail.com, \\ marianakluge@hotmail.com,rafafabres@hotmail.com, \\ chimbicas@hotmail.com, fabricio.bruni@hotmail.com, \\ julianefleck@feevale.br, simonepi@feevale.br, \\ fernandors@feevale.br
}

\section{RESUMO}

O abastecimento de água do município de Ivoti provém unicamente de origem subterrânea. A potabilidade da água subterrânea do município foi avaliada através da análise de marcadores bacterianos (Escherichia coli e coliformes totais) e virais (adenovírus, enterovírus e rotavírus) de contaminação. Vinte e sete amostras de água provenientes de poços artesianos, poços cavados e fontes foram coletadas entre fevereiro e abril de 2011. A determinação do número mais provável (NMP) de E. coli e coliformes totais em $100 \mathrm{~mL}$ foi realizada pelo método dos tubos múltiplos. Os marcadores virais foram analisados em alíquotas de $500 \mathrm{~mL}$ por reação em cadeia da polimerase (PCR). Coliformes totais foram encontrados em $66,6 \%$ das amostras. A contaminação encontrada para coliformes termotolerantes foi de $25,9 \%, 40,7 \%$ para adenovírus e $22,2 \%$ para rotavírus. Nenhuma amostra apresentou enterovírus. A presença de coliformes e de vírus nas amostras indica contaminação fecal da água subterrânea no local de estudo, situado na porção aflorante do Aquífero Guarani e alerta para a necessidade de precaução quanto ao uso destes mananciais para abastecimento público, captação individual e cultivo de hortaliças.

Palavras-chave: adenovírus, Escherichia coli, enterovírus, rotavírus.

\section{Viral and bacterial contamination in groundwater from the Guaraní Aquifer's recharge area, Ivoti municipality, RS}

\begin{abstract}
The water supply of the municipality of Ivoti comes solely from an underground source. The potability of groundwater in the municipality was evaluated by analyzing bacterial (Escherichia coli and total coliforms) and viral (adenovirus, enterovirus and rotavirus) markers for contamination. Twenty-seven water samples from artesian wells, dug wells and springs were collected between February and April 2011. The determination of the most probable number
\end{abstract}


(MPN) of E. coli and total coliforms in $100 \mathrm{~mL}$ was performed by the multiple-tube method. Viral markers were analyzed in $500 \mathrm{~mL}$ aliquots by polymerase chain reaction (PCR). Total coliforms were found in $66.6 \%$ of samples. Contamination found for E. coli was $25.9 \%, 40.7 \%$ for adenovirus and $22.2 \%$ for rotavirus. Enterovirus was not found. The presence of coliform bacteria and viruses in the samples indicates fecal contamination of groundwater at the study site, located in the recharge portion of the Guarani Aquifer and suggests the need of caution regarding the use of these water sources for public water supply, individual water catchment and farming.

Keywords: adenovirus, enterovirus, Escherichia coli, rotavirus.

\section{INTRODUÇÃO}

O município de Ivoti (RS), com população de 19.877 habitantes (IBGE, 2011) e com abastecimento de água de origem unicamente subterrânea, está localizado sobre a porção aflorante do Sistema Aquífero Guarani (SAG). O SAG é a principal reserva de água doce da América do Sul, estendendo-se por territórios uruguaios (3,8\%), paraguaios $(6,1 \%)$, argentinos $(19,1 \%)$ e brasileiros $(71 \%)$ (OEA, 2009). As áreas de afloramento do aquífero, onde a água das chuvas se infiltra para as camadas profundas do solo, representam regiões onde o aquífero se encontra mais vulnerável à contaminação, uma vez que os solos mais permeáveis têm baixa capacidade de reter poluentes (IPT, 2011). Estudos anteriores apontaram uma discrepância entre a demanda e a oferta, com evidentes impactos sobre da disponibilidade hídrica do Aquífero nesta localidade (Coelho et al., 2004). Ainda, a inadequada ocupação do solo e manejo de poluentes podem comprometer a qualidade da água subterrânea (Gomes, 2008). A soma dos riscos de sustentabilidade pode vir a inviabilizar a utilização futura das captações subterrâneas do aquífero (Heine et al., 2011).

Problemas de disponibilidade e a proposta da companhia de abastecimento de buscar como alternativa fontes de água superficial para abastecer o município provocaram protestos da população e a recente municipalização do sistema. A escassez de água superficial e crescentes conflitos sobre seu uso, aliados à dificuldade de obtenção de água doce de outras fontes, tornam o uso de água subterrânea uma alternativa mais atrativa. A água presente na superfície percola o solo e rochas, formando grandes reservatórios subterrâneos em aquíferos. Até os anos 70 acreditava-se que as águas subterrâneas eram mais puras do que águas superficiais, devido à sua limpidez, e protegidas naturalmente de contaminação (Colvara et al., 2009). Parte dessa presunção mantêm-se atualmente, por parte da população geral, e as águas captadas dessas fontes frequentemente não passam por nenhum tipo de tratamento ou descontaminação (Amaral et al., 2003; Schijven et al., 2010).

Todavia, águas subterrâneas nem sempre são uma alternativa mais viável do ponto de vista da qualidade higiênico-sanitária. As águas de poços, mesmo cristalinas, sem odor e aparentemente próprias para consumo, podem conter microrganismos patogênicos (Colvara et al., 2009). É crescente o número de surtos infecciosos transmitidos por via hídrica e de estudos reportando a presença ou traços de contaminantes e patógenos, dentre bactérias, vírus entéricos e protozoários, em águas subterrâneas urbanas e rurais. Na literatura são relatadas contaminações bacterianas por E. coli, Clostridium perfringens e Enterococcus; virais por adenovírus $(\mathrm{AdV})$, enterovírus $(\mathrm{EV})$, rotavírus $(\mathrm{RV})$, vírus da hepatite $\mathrm{A}$, norovírus, e echovírus; além de protozoários e contaminação por uso de pesticidas ou resíduos industriais (De Serres et al., 1999; Fout et al., 2003; Borchardt et al., 2007; Naik et al., 2007; Ribeiro et al., 2007; Colvara et al., 2009; Ogorzaly et al., 2010; Razzolini et al., 2011a; 2011b). O consumo da água contaminada pode causar desde doenças entéricas e hepatites, até o óbito (Schijven et al., 2010; Lenaerts et al., 2008). 
A contaminação dos aquíferos ocorre principalmente pela precipitação e infiltração de aterros sanitários, utilização de fossas sépticas como destinação final de esgoto urbano e perdas de volume no transporte ou entupimento de trechos da rede de condutos pluviais. Além destas, a contaminação pode ocorrer por infiltrações de redes de esgoto e percolação a partir de lagoas de estabilização, infiltrações de compostos industriais, vazamentos de tanques de combustível, uso de fertilizantes e tanques de reservas de resíduos animais e migração de microrganismos através do solo. Poços artesianos ou cavados construídos desordenadamente não apresentam revestimentos, filtros ou elementos de proteção sanitária, podendo servir de aporte para contaminantes via escoamento superficial e paredes permeáveis (Piranha e Pacheco, 2004). Ainda que a fonte de água seja potável, a qualidade da água pode ficar comprometida no transporte até o ponto de uso, caso não haja tratamento da água e limpeza periódica do local de armazenamento (Amaral et al., 2003).

A legislação brasileira estabelece as bactérias do grupo coliforme como principal parâmetro microbiológico de potabilidade (Brasil, 2011). Essas bactérias, porém, não são representativas de outros microrganismos com perfis de sobrevivência diferentes. Sua presença ou ausência não apresenta correlação com outras bactérias patogênicas, protozoários, parasitas ou vírus entéricos (Wong et al., 2009). Vírus entéricos, como os AdV, família Adenoviridae, gênero Mastadenovírus, EV, ordem Picornavirales, família Picornaviridae, gênero Enterovirus, ou os RV, família Reoviridae, subfamília Sedoreovirinae, gênero Rotavirus, apresentam-se como adequados indicadores auxiliares de contaminação fecal, uma vez que são transmitidos por via fecal-oral e são de veiculação hídrica, podem ser encontrados ao longo de todo ano e estão presentes, com frequência, em amostras ambientais contaminadas por escoamento urbano ou rural. Possuem resistência aos tratamentos convencionais de água e esgoto, elevada persistência (Jiang et al., 2001) e a presença desses três vírus já foi demonstrada em águas superficiais e subterrâneas de Porto Alegre, Caxias do Sul, Pelotas, Santa Maria e diversos outros municípios do Rio Grande do Sul (RS) (Luz et al., 2012; Oliveira et al., 2012; Vecchia et al., 2012a; Vecchia et al., 20012b). As partículas virais têm facilidade de penetração e migração através solo, podendo ser transportadas por distâncias superiores à um quilômetro ou adentrar lençóis freáticos pelo escoamento superficial de águas contaminadas, atingindo águas subterrâneas através de poços e aberturas naturais ou artificiais (De Serres et al., 1999; Piranha e Pacheco, 2004). Esses vírus possuem dose infectante extremamente baixa e capacidade de persistirem viáveis por mais de um ano (Ogorzaly et al., 2010).

O presente trabalho buscou avaliar, por parâmetros microbiológicos clássicos previstos na Portaria MS 2914/2011, coliformes totais (CT) e E. coli, e pela detecção de adenovírus (AdV), enterovírus (EV) e rotavírus (RV), a qualidade e segurança microbiológica da água subterrânea em uma localidade onde o recurso hídrico oriundo de porções do SAG é a fonte exclusiva de abastecimento público e frequentemente utilizado no cultivo de hortaliças.

\section{MATERIAL E MÉTODOS}

Entre fevereiro e abril de 2011, vinte e sete amostras de água de diferentes poços artesianos (com maior profundidade e sem necessidade de bombeamento da água), poços cavados (com menor profundidade e necessidade de maquinária para a retirada da água) e fontes (vertentes com brotamento de água subterrânea) no perímetro de Ivoti, RS, foram coletadas assepticamente em alíquotas de 500 e $100 \mathrm{~mL}$ e permaneceram sob refrigeração até serem processadas. A amostragem deu-se por conveniência, buscando abranger as áreas mais densamente povoadas no ambiente rural e no núcleo urbano do município. A pesquisa foi feita nos meses de fevereiro a abril, por ser esta uma época de regularidade do regime hídrico da região; os poços amostrados não recebiam cloração e não há informação quanto à outorga do 
uso da água no Departamento de Recursos Hídricos do RS (DRH-RS), à exceção dos poços voltados ao uso industrial. Os pontos de coleta estão representados na Figura 1.

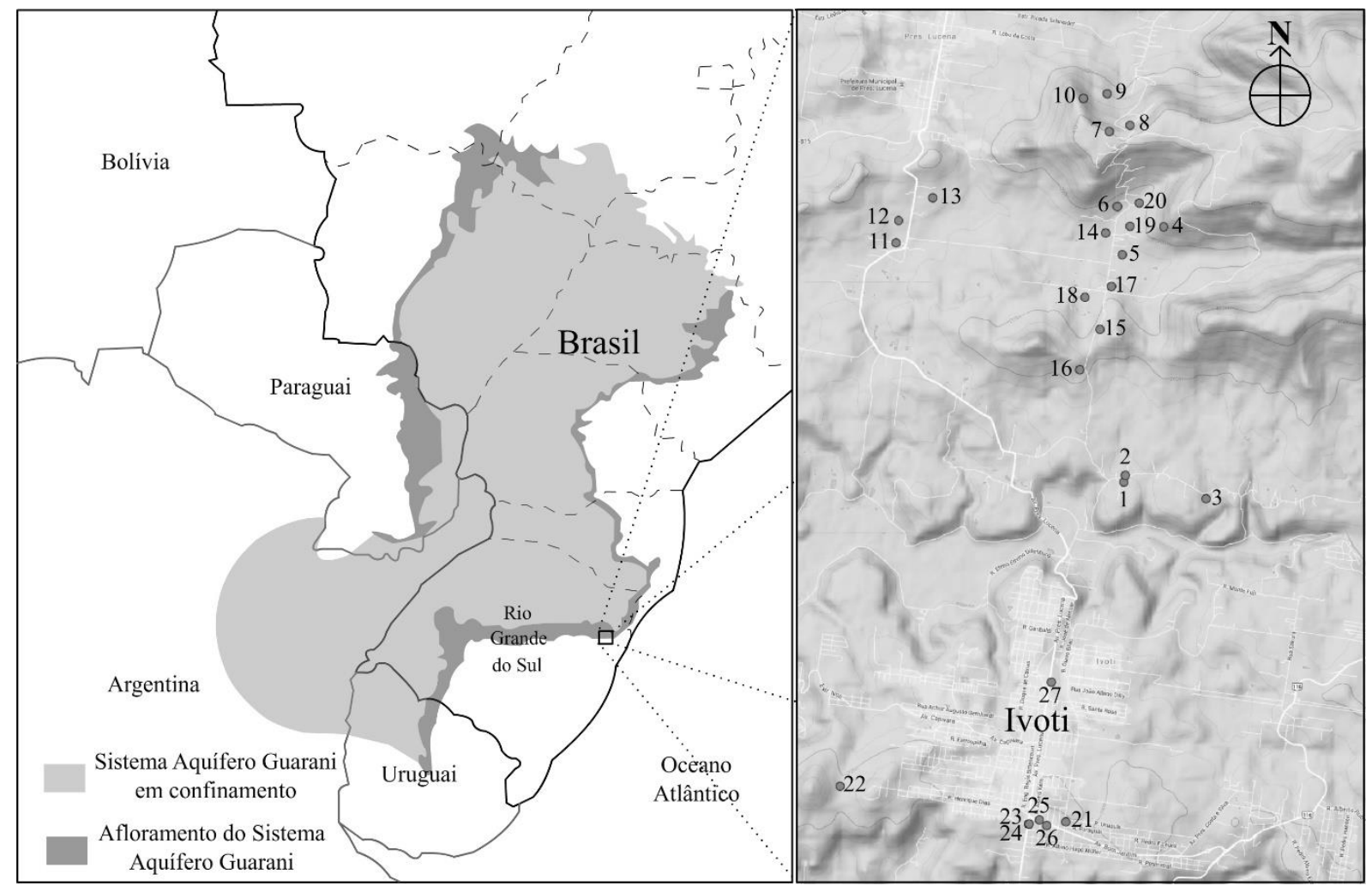

Figura 1. Pontos de Coleta, Ivoti, RS, Brasil.

Para a análise viral, as alíquotas de $500 \mathrm{~mL}$ foram concentradas por adsorção-eluição, conforme metodologia descrita por Katayama et al. (2002), com pequenas modificações. Brevemente $0,6 \mathrm{mg}$ de $\mathrm{MgCl}_{2}$ foram adicionados em cada amostra e o $\mathrm{pH}$ foi ajustado à $5 \pm 0,5$ com solução $\mathrm{HCl} 10 \%$. As amostras foram filtradas através de membranas de nitrocelulose negativamente carregadas (0,45 micra, $47 \mathrm{~mm}$ de diâmetro; HA millipore, EUA). As membranas foram lavadas com $87,5 \mathrm{~mL}^{\text {de } \mathrm{H}_{2} \mathrm{SO}_{4}} 0,5 \mathrm{mM}$ e $2,5 \mathrm{~mL}$ de $\mathrm{NaOH} 1 \mathrm{mM}$. O conteúdo final foi neutralizado com $12,5 \mu \mathrm{L}$ de $\mathrm{H}_{2} \mathrm{SO}_{4} 50 \mathrm{mM}$ e $12,5 \mu \mathrm{L}$ de tampão Tris-EDTA 100x. O filtrado foi armazenado em freezer a $-80^{\circ} \mathrm{C}$. O DNA viral foi extraído com kit de extração RTP DNA/RNA Virus Mini Kit (Invitek ${ }^{\circledR}$, Alemanha), conforme instruções do fabricante. Para a análise de EV e RV, vírus de RNA, a síntese do DNA complementar foi realizada com o kit High Capacity cDNA Reverse Transcription Kit (Applied Biosciences ${ }^{\circledR}$, EUA), inibidor de RNAse (Applied Biosciences ${ }^{\circledR}$ ) e iniciadores randômicos, conforme instruções do fabricante. As reações em cadeia da polimerase (PCR) transcorreram com os seguintes iniciadores e condições: (1) AdV,: iniciadores VTB2-R e VTB2-F, descritos por Wolf et al. (2010); $98^{\circ} \mathrm{C}$ por $7 \mathrm{~min}, 40$ ciclos a $94^{\circ} \mathrm{C}$ por $1 \mathrm{~min}, 55^{\circ} \mathrm{C}$ por $1 \mathrm{~min}, 72^{\circ} \mathrm{C}$ por $1 \mathrm{~min}$; (2) EV, iniciadores ENT-F1, descrito por Tsai et al. (1993) e ENT-F2, por Vecchia et al. (2012a); $98^{\circ} \mathrm{C}$ por $5 \mathrm{~min}, 35$ ciclos a $94^{\circ} \mathrm{C}$ por $1 \mathrm{~min}, 56^{\circ} \mathrm{C}$ por $1 \mathrm{~min}, 72^{\circ} \mathrm{C}$ por $1 \mathrm{~min}$; (3) RV, iniciadores ROTAFEEVALE-FW e ROTAFEEVALE-REV, descritos por Vecchia et al. (2012b); $94^{\circ} \mathrm{C}$ por $5 \mathrm{~min}, 40$ ciclos a $94^{\circ} \mathrm{C}$ por $1 \mathrm{~min}, 54^{\circ} \mathrm{C}$ por $1 \mathrm{~min}$ (decaindo $0,5^{\circ} \mathrm{C}$ a cada ciclo subsequente), $72^{\circ} \mathrm{C}$ por $1 \mathrm{~min}$. Em todas as reações, a elongação ocorreu por 7 min a $72^{\circ} \mathrm{C}$. Poliovírus tipo 1 (cepa Sabin), fornecido pelo Dr. Carlos Nozawa; AdV humano tipos 2 e 5, fornecidos pela Dr. ${ }^{a}$ Célia Barardi e RV humano isolado de amostra clínica (Vecchia et al., 2012a) foram usados como controles positivos; Água ultrapura foi usada como controle negativo. As reações foram realizadas em termociclador (MultiGene, Labnet International, 
EUA). O produto da PCR foi corado com fluorófulo Blue Green (LGCBio, Brasil) e analisado por eletroforese em gel de agarose $2 \%$. A visualisação dos amplicons de AdV, EV e RV, de 101 pares de bases (pb), $116 \mathrm{pb}$ e $160 \mathrm{pb}$, respectivamente, ocorreu sob luz ultravioleta. As análises foram realizadas no Laboratório de Microbiologia Molecular, da Universidade Feevale, Novo Hamburgo, RS.

A determinação dos números mais prováveis (NMP) de CT e E. coli foi realizada através da metodologia dos tubos múltiplos, segundo o método preconizado pela APHA (1995), no Laboratório de Biomedicina, da Universidade Feevale, Novo Hamburgo, RS. A detecção presuntiva de CT foi realizada em Caldo Lactosado e a confirmatória em Caldo Verde Brilhante e Bile 2\%. A detecção de E. coli foi realizada em Caldo E.C., seletivo para o crescimento de Escherichia coli. As amostras foram incubadas à $35 \pm 2{ }^{\circ} \mathrm{C}$ por 48 horas e $44,5 \pm 0,2^{\circ} \mathrm{C}$ por 24 horas, nos testes para CT e $E$. coli, respectivamente. Os resultados dos tubos positivos foram interpretados segundo a Tabela de NMP/dL.

\section{RESULTADOS E DISCUSSÃO}

Das 27 amostras analisadas, $18(66,6 \%)$ foram positivas para CT e sete $(25,9 \%)$ para $E$. coli. Para AdV, $11(40,7 \%)$ amostras analisadas foram positivas, e seis $(22,2 \%)$ para RV. Nenhuma amostra foi positiva para EV. Dos 17 poços que apresentaram contaminação por E. coli, AdV ou RV, 14 destinam-se à consumo humano e um à irrigação. Os resultados estão apresentados na Tabela 1.

A portaria 2914/2011 do Ministério da Saúde estipula a ausência de E. coli em $100 \mathrm{~mL}$ de água como padrão microbiológico da água para consumo humano (Brasil, 2011). As análises apontam que 1/4 dos poços testados não atendem a este padrão, por apresentarem contaminação por E. coli. O consumo de água contaminada por material fecal pode representar riscos e agravos à saúde. Praticamente $67 \%$ das amostras apresentaram presença de CT, indicando falha da integridade do sistema de distribuição de água do município no período analisado. Dados mais recentes sugerem melhoria no reservatório e rede de distribuição, uma vez que em 2012 menos de $1 \%$ de amostras testadas apresentou resultado fora do padrão (SNIS, 2014), embora a quantidade de amostras analisadas esteve abaixo do limite mínimo recomentado pela portaria 2914/2011. Não há dados sobre E. coli no SNIS, uma vez que o município não realiza tratamento de água e tratamento de esgoto.

A legislação brasileira é vaga em relação à presença e monitoramento de vírus entéricos na água, constando apenas como recomendação ou análise em caso de surtos. A frequência da contaminação viral de água subterrânea encontrada é consideravelmente superior à de outros países, como Coreia do Sul (Park et al., 2010), EUA (Ogorzaly et al., 2010) ou África (Verheyen et al., 2009), com contaminação em 3,2\%, 11,6\% e 12,9\% dos poços analisados, respectivamente, porém está de acordo com outros estudos realizados no Brasil. Em São Paulo, houve contaminação em 53,3\% dos poços em área rural (Piranha e Pacheco, 2004) e 66,6\% de contaminação em aquífero freático de um cemitério (Matos e Pacheco, 2002). Em trabalho realizado no estado de Santa Catarina, todos os poços analisados em uma área de produção suinícola apresentaram AdV humano e suíno (Garcia et al., 2012). No Estado do Rio Grande do Sul, no município de Tenente Portela, a presença de AdV na porção de confinamento do SAG demonstrou contaminação em $100 \%$ dos pontos amostrados em fazendas de produção leiteira (Spilki et al., 2013), podendo indicar contaminação proveniente das áreas de recarga do aquífero. O município de Riozinho apresentou contaminação por AdV e RV em 50\% dos poços de propriedades rurais e em Rolante, 66,6\% e 55,5\%, respectivamente (Staggemeier et al., 2015). Em amostras provenientes do município de Taquara (RS), a frequência de contaminação era de $66,6 \%$ para RV, 50\% para AdV e 16,6\% para EV (dados não publicados). 
Tabela 1. Resultados das análises de coliformes totais (CT), E. coli, Adenovírus (AdV), Enterovírus (EV) e Rotavírus (RV) em amostras de água subterrânea, Ivoti (RS).

\begin{tabular}{|c|c|c|c|c|c|c|}
\hline Identificação & $\begin{array}{c}\mathrm{CT} \\
(\mathrm{NMP} / \mathrm{dL})\end{array}$ & $\begin{array}{c}\text { E. coli } \\
(\mathrm{NMP} / \mathrm{dL})\end{array}$ & $\mathrm{AdV}$ & EV & RV & $\begin{array}{c}\text { Utilização } \\
\text { da água }\end{array}$ \\
\hline Amostra 1 - Poço Cavado & $>1.100$ & $<3$ & Positivo & Negativo & Negativo & $\begin{array}{l}\text { Criação de } \\
\text { aves }\end{array}$ \\
\hline Amostra 2 - Poço Artesiano & 240 & 9,1 & Negativo & Negativo & Negativo & Consumo \\
\hline Amostra 3 - Poço Cavado & $>1.100$ & 460 & Positivo & Negativo & Negativo & $\begin{array}{l}\text { Consumo/ } \\
\text { Limpeza } \\
\text { Industrial }\end{array}$ \\
\hline Amostra 4 - Poço Artesiano & 1.100 & $<3$ & Negativo & Negativo & Negativo & Consumo \\
\hline Amostra 5 - Poço Artesiano & 9,1 & 3,6 & Positivo & Negativo & Negativo & Consumo \\
\hline Amostra 6 - Fonte & 460 & 460 & Positivo & Negativo & Negativo & Consumo \\
\hline Amostra 7 - Poço Artesiano & 93 & $<3$ & Positivo & Negativo & Negativo & $\begin{array}{l}\text { Limpeza } \\
\text { Industrial }\end{array}$ \\
\hline Amostra 8 - Fonte & 19 & $<3$ & Negativo & Negativo & Negativo & Consumo \\
\hline Amostra 9 - Fonte & 1.100 & $<3$ & Positivo & Negativo & Negativo & Consumo \\
\hline Amostra 10 - Fonte & 1.100 & 21 & Negativo & Negativo & Negativo & Consumo \\
\hline Amostra 11 - Poço Artesiano & $<3$ & $<3$ & Negativo & Negativo & Negativo & Consumo \\
\hline Amostra 12 - Poço Artesiano & 43 & $<3$ & Positivo & Negativo & Negativo & Consumo \\
\hline Amostra 13 - Poço Artesiano & $<3$ & $<3$ & Positivo & Negativo & Positivo & Consumo \\
\hline Amostra 14 - Poço Artesiano & $<3$ & $<3$ & Positivo & Negativo & Negativo & Irrigação \\
\hline Amostra 15 - Poço Artesiano & $<3$ & $<3$ & Negativo & Negativo & Positivo & Consumo \\
\hline Amostra 16 - Poço Artesiano & 23 & $<3$ & Negativo & Negativo & Positivo & Consumo \\
\hline Amostra 17 - Poço Artesiano & $<3$ & $<3$ & Positivo & Negativo & Positivo & Consumo \\
\hline Amostra 18 - Poço Artesiano & $<3$ & $<3$ & Negativo & Negativo & Negativo & Consumo \\
\hline Amostra 19 - Poço Artesiano & 240 & 9,1 & Negativo & Negativo & Positivo & Consumo \\
\hline Amostra 20 - Poço Artesiano & $<3$ & $<3$ & Positivo & Negativo & Negativo & Consumo \\
\hline Amostra 21 - Poço Artesiano & 3 & $<3$ & Negativo & Negativo & Negativo & Consumo \\
\hline Amostra 22 - Poço Artesiano & 93 & $<3$ & Negativo & Negativo & Negativo & Consumo \\
\hline Amostra 23 - Poço Artesiano & $<3$ & $<3$ & Negativo & Negativo & Negativo & Consumo \\
\hline Amostra 24 - Poço Cavado & 150 & $<3$ & Negativo & Negativo & Negativo & Limpeza \\
\hline Amostra 25 - Poço Artesiano & 29 & 3,6 & Negativo & Negativo & Negativo & Consumo \\
\hline Amostra 26 - Poço Cavado & 53 & $<3$ & Negativo & Negativo & Positivo & Limpeza \\
\hline Amostra 27 - Fonte & $<3$ & $<3$ & Negativo & Negativo & Negativo & Consumo \\
\hline
\end{tabular}

Mesmo sem valor epidemiológico e sem parâmetros legais de comparação, os resultados do estudo, associados aos da literatura, demonstram contaminação fecal (Abbaszadegan et al., 1999) e comprometimento da água do SAG. A crescente depleção nos níveis de água subterrânea em Ivoti (Heine et al., 2011) e a contaminação demonstrada podem colocar em 
risco à segurança hídrica do RS e do Brasil se considerarmos que as águas da região são drenadas sem tratamento para a Bacia do Rio Caí, um dos principais componentes da região hidrográfica do Lago Guaíba, e que a área afetada é uma das principais áreas de recarga da maior reserva de água subterrânea da América do Sul. Apenas o isolamento da superfície e filtração natural durante a percolação da água aos aquíferos, não parecem ser capazes de garantir a potabilidade. Medidas de proteção são necessárias para a manutenção da qualidade natural das águas e sustentabilidade do aquífero (IPT, 2011; Heine et al., 2011). A portaria, como se apresenta, aparenta ser propositalmente esparsa de modo a manter um sistema ininterrupto de abastecimento urbano que não causa ônus corporativos e não prioriza a qualidade da água e saúde pública (Hupffer et al., 2013). Evidencia-se, portanto, a necessidade de uma legislação que acompanhe os desenvolvimentos científicos na área da saúde e ambiental e a elaboração de um plano de desenvolvimento, proteção ambiental e gestão do SAG, tanto em âmbito estadual, quanto nacional.

\section{CONCLUSÃO}

Os resultados de contaminação por E. coli, AdV e RV, demonstram impacto por poluição fecal nas águas subterrâneas do município de Ivoti. A filtração natural do solo em regiões de recarga não é capaz de garantir a potabilidade da água e é recomendado o tratamento prévio ao consumo. O disciplinamento da ocupação territorial, abertura e manutenção de poços, investimentos em saneamento e legislação mais eficaz se fazem necessários para manter a sustentabilidade do SAG. O monitoramento de indicadores microbiológicos clássicos e auxiliares é recomendado para que medidas corretas de preservação do aquífero possam ser tomadas.

\section{REFERÊNCIAS}

ABBASZADEGAN, M. et al. A Strategy for Detection of Viruses in Groundwater by PCR. Applied and Environmental Microbiology, v.65, n. 2, p. 444-449, 1999.

AMARAL, L. A. et al. Água de consumo humano como fator de risco à saúde em propriedades rurais. Revista de Saúde Pública, v. 37, n. 4, p. 510-514, 2003. http://dx.doi.org/10.1590/S0034-89102003000400017

AMERICAN PUBLIC HEALTH ASSOCIATION - APHA. Standard Methods for the Examination of Water and Wastewater. $19^{\text {th }}$ ed. Nova York, 1995.

BORCHARDT, M. A. et al. Human Enteric Viruses in Groundwater from a Confined Bedrock Aquifer. Environmental Science \& Technology, v.41, n.18, p.6606-6612, 2007. http://dx.doi.org/10.1021/es071110+

BRASIL. Ministério da Saúde. Portaria No 2914, de 12 e dezembro de 2011. Dispõe sobre os procedimentos de controle e de vigilância da qualidade da água para consumo humano e seu padrão de potabilidade. Diário Oficial [da] União, Brasília, n. 239, 14 dez. 2011, seção 1, p. 39-46.

COELHO, O. G. W. et al. Estimativa da variação de armazenamento do sistema aqüífero Guarani em Ivoti-RS: uma aplicação de técnicas de geoprocessamento no planejamento do abastecimento público. Acta Geológica Leopoldensia, p. 1-11, 2004.

COLVARA, J. G. et al. Avaliação da contaminação de água subterrânea em poços artesianos no sul do Rio Grande do Sul. Brazilian Journal of Food Technology, II SSA, 2009. 
DE SERRES, G. et al. Molecular confirmation of hepatitis A virus from well water: epidemiology and public health implications. The Journal of Infectious Disease, v. 179, n. 1, p. 37-43, 1999. http://dx.doi.org/10.1086/314565

FOUT, G. S. et al. A multiplex reverse transcription-PCR method for detection of human enteric viruses in groundwater. Applied and Environmental Microbiology, v.69, n.6, p.31583164, 2003. http://dx.doi.org/10.1128/AEM.69.6.3158-3164.2003

GARCIA, L. A. et al. Surveillance of human and swine adenovirus, human norovirus and swine circovirus in water samples in Santa Catarina, Brazil. Journal of Water and Health, v.10, n.3, p.445-452, 2012. http://dx.doi.org/10.2166/wh.2012.190

GOMES, M. A. F. Uso agrícola das áreas de afloramento do Aquífero Guarani no Brasil: implicações para a água subterrânea e propostas de gestão com enfoque agroambiental. Brasília: EMBRAPA, 2008. 417p.

HEINE, C. A. et al. Avaliação preliminar da sustentabilidade do Sistema Aqüífero Guarani no município de Ivoti - RS. Águas Subterrâneas, n. 1, p. 1-9, 2011.

HUPFFER, H. M. et al. A flacidez da legislação brasileira em relação aos patógenos emergentes 3. Revista de Direito Ambiental, v. 69, p. 315-333, 2013. http://bdjur.stj.jus.br/dspace/handle/2011/77898

INSTITUTO BRASILEIRO DE GEOGRAFIA E ESTATÍSTICA - IBGE. Censo Demográfico 2010. Rio de Janeiro, 2011.

INSTITUTO DE PESQUISAS TECNOLÓGICAS - IPT. Subsídios ao plano de desenvolvimento e proteção ambiental da área de afloramento do sistema aquífero Guarani no estado de São Paulo. São Paulo, 2011.

JIANG, S. et al. Human Adenoviruses and Coliphages in Urban Runoff-Impacted Coastal Waters of Southern California. Applied and Environmental Microbiology, v. 67, n. 1, p. 179-184, 2001. http://dx.doi.org/10.1128/AEM.67.1.179-184.2001

KATAYAMA, H. et al. Development of a Virus Concentration Method and Its Application to Detection of Enterovirus and Norwalk Virus from Coastal Seawater. Applied and Environmental Microbiology, v. 68, n. 3, p. 1033-1039, 2002. http://dx.doi.org/10.1128/AEM.68.3.1033-1039.2002

LENAERTS, L. et al. Clinical features and treatment of adenovirus infections. Reviews in Medical Virology, v. 18, n. 6, p. 357-374, 2008. http://dx.doi.org/10.1002/rmv.589

LUZ, R. B. et al. Presença de partículas virais infecciosas em amostras de água de diferentes tipos e localidades do Rio Grande do Sul, Brasil. Revista Brasileira de Biociências, v. 10, n. 1, p. 103-106, 2012.

MATOS, B.; PACHECO, A. Avaliação da ocorrência e do transporte de microrganismos no aqüífero freático do cemitério de Vila Nova Cachoeirinha, município de São Paulo. In: CONGRESSO BRASILEIRO DE ÁGUAS SUBTERRÂNEAS, 12., 2002, Florianópolis. Livro de resumos... Florianópolis, 2002. p. 1-21.

NAIK, P. K. et al. Groundwater pollution around an industrial area in the coastal stretch of Maharashtra State, India. Environmental Monitoring and Assessment, v. 132, n. 1-3, p. 207-233, 2007. http://dx.doi.org/10.1007/s10661-006-9529-6 
ORGANIZAÇÃO DOS ESTADOS AMERICANOS - OEA. Aquífero Guarani: programa estratégico de ação. Brasília, 2009. 424 p.

OLIVEIRA, L. K. et al. Enteric viruses in water samples from Brazilian dairy farms. $\begin{array}{lllllll}\text { Agricultural Water } & \text { Management, } & \text { v. } 111, \quad \text { p. }\end{array}$ http://dx.doi.org/10.1016/j.agwat.2012.05.001

OGORZALY, L. et al. Occurrence, Survival, and Persistence of Human Adenoviruses and FSpecific RNA Phages in Raw Groundwater. Applied and Environmental Microbiology, v. 76, n. 24, p. 8019-8025, 2010. http://dx.doi.org/10.1128/AEM.00917-10

PARK, S. H. et al. Human Enteric Viruses in Groundwater. Food and Environmental Virology, v. 2, n. 2, p. 69-73, 2010. http://dx.doi.org/10.1007/s12560-010-9029-2

PIRANHA, J. M.; PACHECO, A. Vírus em águas subterrâneas usadas para abastecimento de comunidades rurais do município de São José do Rio Preto (SP). In: CONGRESSO BRASILEIRO DE ÁGUAS SUBTERRÂNEAS, 13., 2004, Cuiabá. Livro de resumos... Cuiabá: DNPM, 2004. p. 1-15.

RAZZOLINI, M. T. P. et al. Quality of water sources used as drinking water in a Brazilian periurban area. Brazilian Journal of Microbiology, v. 42, n. 2, p. 560-566, 2011 a. http://dx.doi.org/10.1590/S1517-83822011000200021

RAZZOLINI, M. T. P. et al. Risk of Giardia infection for drinking water and bathing in a periurban area in São Paulo, Brazil. International Journal of Environmental Health Research, v. 21, n. 3, p. 1-13, 2011b. http://dx.doi.org/10.1080/09603123.2010.533367

RIBEIRO, M. L. et al. Contaminação de águas subterrâneas por pesticidas: avaliação

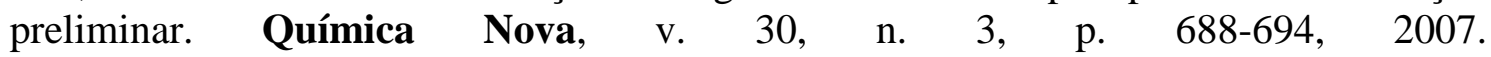
http://dx.doi.org/10.1590/S0100-40422007000300031

SCHIJVEN, J. F. et al. Vulnerability of unconfined aquifers to virus contamination. Water Research, v.44, p.1170-1181, 2010. https://doi.org/10.1016/j.watres.2010.01.002

SISTEMA NACIONAL DE INFORMAÇÕES SOBRE SANEAMENTO - SNIS. Série Histórica - Informações e indicadores municipais consolidados. 2014. Disponível em: www.cidade.gov.br/serieHistorica. Acesso em: 1 nov. 2014.

SPILKI, F. R. et al. Detection of adenovirus, rotavirus and enterovirus in water samples collected on dairy farms from Tenente Portela, Northwest of Rio Grande do Sul, Brazil. Brazilian Journal of Microbiology, v. 44, n. 3, p. 953-957, 2013. http://dx.doi.org/10.1590/S1517-83822013000300046

STAGGEMEIER, R. et al. Animal and human enteric viruses in water and sediment samples from dairy farms. Agricultural Water Management, v. 152, p. 135-141, 2015. http://dx.doi.org/10.1016/j.agwat.2015.01.010

TSAI, Y. L. et al. Simple method of concentrating enteroviruses and hepatitis A virus from sewage and ocean water for rapid detection by reverse transcriptase-polymerase chain reaction. Applied and Environmental Microbiology, v. 59, n. 10, p. 3488-3491, 1993.

VECCHIA, A. D. et al. First description of Adenovirus, Enterovirus, Rotavirus and Torque teno virus in water samples collected from the Arroio Dilúvio, Porto Alegre, Brazil. Brazilian Journal of Biology, v. 72, n. 2, p. 1-7, 2012a. 
VECCHIA, A. D. et al. Assessment of enteric viruses in a sewage treatment plant located in Porto Alegre, southern Brazil. Brazilian Journal of Biology, v. 72, n. 4, p. 839-846, 2012b.

VERHEYEN, J. et al. Detection of Adenoviruses and Rotaviruses in Drinking Water Sources Used In Rural Areas of Benin, West Africa. Applied and Environmental Microbiology, v. 75, n. 9, p. 2798-2801, 2009. http://dx.doi.org/10.1128/AEM.01807-08

WONG, M. et al. Evaluation of public health risks at recreational beaches in Lake Michigan via detection of enteric viruses and a human-specific bacteriological marker. Water $\begin{array}{lllllll}\text { Research, } & \text { v. } & 43, & \text { n. } & 4, & \text { p. } & 1137-1149,\end{array}$ http://dx.doi.org/10.1016/j.watres.2008.11.051

WOLF, S. et al. Viral Multiplex Quantitative PCR Assays for Tracking Sources of Fecal Contamination. Applied and Environmental Microbiology, v. 76, n. 5, p. 1388-1394, 2010. http://dx.doi.org/10.1128/AEM.02249-09 